\title{
Hybrid Acrylated Chitosan and Thiolated Pectin Cross-Linked Hydrogels with Tunable Properties
}

\author{
Shaked Eliyahu ${ }^{1}$, Alexandra Galitsky ${ }^{2}$, Esther Ritov ${ }^{2}$ and Havazelet Bianco-Peled ${ }^{1,2, *}$ \\ 1 The Russell Berrie Nanotechnology Institute, Technion-Israel Institute of Technology, Haifa 3200003, Israel; \\ shaked@campus.technion.ac.il \\ 2 Department of Chemical Engineering, Technion-Israel Institute of Technology, Haifa 3200003, Israel; \\ gsashaaa@gmail.com (A.G.); esty.ritov@gmail.com (E.R.) \\ * Correspondence: bianco@technion.ac.il; Tel.: +972-4-829-3588
}

Citation: Eliyahu, S.; Galitsky, A.; Ritov, E.; Bianco-Peled, H. Hybrid Acrylated Chitosan and Thiolated Pectin Cross-Linked Hydrogels with Tunable Properties. Polymers 2021, 13, 266. https://doi.org/10.3390/ polym 13020266

Received: 20 December 2020 Accepted: 11 January 2021 Published: 14 January 2021

Publisher's Note: MDPI stays neutral with regard to jurisdictional clai$\mathrm{ms}$ in published maps and institutional affiliations.

Copyright: $(2021$ by the authors. Licensee MDPI, Basel, Switzerland. This article is an open access article distributed under the terms and conditions of the Creative Commons Attribution (CC BY) license (https:// creativecommons.org/licenses/by/ $4.0 /)$.

\begin{abstract}
We developed and characterized a new hydrogel system based on the physical and chemical interactions of pectin partially modified with thiol groups and chitosan modified with acrylate end groups. Gelation occurred at high pectin thiol ratios, indicating that a low acrylated chitosan concentration in the hydrogel had a profound effect on the cross-linking. Turbidity, Fourier transform infrared spectroscopy, and free thiol determination analyses were performed to determine the relationships of the different bonds inside the gel. At low $\mathrm{pH}$ values below the $\mathrm{pKa}$ of chitosan, more electrostatic interactions were formed between opposite charges, but at high $\mathrm{pH}$ values, the Michael-type addition reaction between acrylate and thiol took place, creating harder hydrogels. Swelling experiments and Young's modulus measurements were performed to study the structure and properties of the resultant hydrogels. The nanostructure was examined using small-angle $X$-ray scattering. The texture profile analysis showed a unique property of hydrogel adhesiveness. By implementing changes in the preparation procedure, we controlled the hydrogel properties. This hybrid hydrogel system can be a good candidate for a wide range of biomedical applications, such as a mucosal biomimetic surface for mucoadhesive testing.
\end{abstract}

Keywords: acrylated chitosan; thiolated pectin; hybrid hydrogels; mucosal mimetic; polysaccharide hydrogels

\section{Introduction}

Polysaccharide-based hydrogels are three-dimensional structured networks with great water absorbance ability. As they are biodegradable and biocompatible, they are utilized for a wide range of biomedical applications, such as regenerative medicine and sustained drug release systems [1-4].

Chitosan is a cationic biocompatible polysaccharide derived from the deacetylation of the acetyl group in chitin and is soluble below its pKa of 6.2-7.0 [5]. It has emerged as a promising polymer for biomedicine applications, including nanosystems, films, and hydrogels [6,7]. Pectin is an anionic polysaccharide extracted from plants' middle lamella and primary cell walls. This polymer is mainly utilized as a thickening and gelling agent in the food industry, but it is also widely studied for drug delivery systems in the pharmaceutical field. The pKa of pectin is around 2.9-3.2 [8]. A mixture of pectin and chitosan has been found to form stable hydrogels [9]. Such hydrogels can be fabricated by mixing the hot acidic solutions of the polymers where the cross-linking occurs due to hydrogen bonding formation upon cooling [10]. Pectin chitosan thermo-reversible hydrogels have been examined for pharmaceutical applications, but their acidic $\mathrm{pH}$ limits their range of use [8]. Alternatively, hydrogels based on a polyelectrolyte complex between pectin and chitosan are formed by establishing strong and attractive interactions in a wider pH range [11]. However, it was pointed out by Bernabé and coworkers that chitosan-pectin complex membranes would be totally destroyed at extreme $\mathrm{pH}$ values [12]. 
Therefore, the incorporation of another cross-linking method can improve certain properties, such as swelling ability, gel strength, and thermal stability. Chemical crosslinking has the advantages of endurance and stability, but it typically requires the presence of UV light and/or a chemical precursor, which is usually cytotoxic [13]. To overcome these limitations, the Michael-type addition reaction can be implemented. This reaction is typically free of byproducts and can occur without catalysts because of its mechanism [14-17].

In this work, we developed and characterized a new one-pot hydrogel system based on the physical and chemical interactions of acrylated chitosan and thiolated pectin. Acrylated chitosan was previously synthesized by grafting poly (ethylene glycol) diacrylate (PEGDA) chains on a chitosan backbone and was evaluated as a mucoadhesive polymer by Shitrit et al. [18]. Thiolated pectin is produced by conjugating pectin with molecules carrying free thiol functionality, usually cysteines [19]. In this hybrid system, physical interactions are formed between the positively charged amine on the chitosan backbone and the negatively charged carboxylic acid in pectin. The chemical reaction is mediated using the Michael-type addition reaction between thiol and acrylate. This dual cross-linking enabled hydrogel preparation in various conditions. We analyzed the gelation process in different conditions to investigate the involvement of the different interactions: above the $\mathrm{pKa}$ of pectin and below the $\mathrm{pKa}$ of chitosan in two $\mathrm{pH}$ values and above the $\mathrm{pKa}$ of pectin and chitosan. The hydrogels were evaluated using Fourier transform infrared spectroscopy (FTIR), turbidity measurements, and free thiol determination. The mechanical properties, swelling, and hydrogel adhesion were characterized. To the best of our knowledge, this is the first time such hydrogels have been described.

\section{Materials and Methods}

\subsection{Materials}

Low-molecular-weight chitosan (molecular weight of $207 \mathrm{kDa}$, deacetylation degree of 77.6\%), 5,5'-dithiobis(2-nitro-benzoic acid) (Ellman's reagent), and fluorescamine were obtained from Sigma Aldrich (Rehovot, Israel). Sodium tripolyphosphate was purchased from Alfa Aesar (Lancashire, UK). Sodium chloride and $\mathrm{NaOH}$ were obtained from Bio-Lab Ltd. (Jerusalem, Israel). Acetic acid glacial, dimethyl sulfoxide (DMSO), $\mathrm{Na}_{2} \mathrm{HPO}_{4}, \mathrm{NaH}_{2} \mathrm{PO}_{4}$ ${ }^{*} \mathrm{H}_{2} \mathrm{O}, \mathrm{KH}_{2} \mathrm{PO}_{4}$, sodium acetate and L-cysteine monohydrate hydrochloride were purchased from Merck (Darmstadt, Germany). Potassium chloride was obtained from Nile Chemicals (Mumbai, India). PEGDA with a molecular weight of $10 \mathrm{kDa}$ was obtained from the laboratory of Biomaterials and Regenerative Medicine at the Department of Biomedical Engineering, Technion, Israel. 1-Ethyl-3-(3-dimethylaminopropyl)-carbodiimide hydrochloride (EDAC) was purchased from Tzamal D-Chem (Petach Tikva, Israel). Classic citrus pectin (CU 701; degree of esterification of $34 \%$, GalA of $86 \%$ ) was kindly donated by Herbstreith \& Fox (Neuenbürg, Germany).

\subsection{Buffer Preparation}

\subsubsection{Acetate Buffer}

To prepare the acetate buffer, acetic acid was dissolved in double distilled water (DDW) to a final concentration of $0.1 \mathrm{M}$, while a powder of sodium acetate was dissolved in DDW to the same final concentration of $0.1 \mathrm{M}$. To obtain a buffer solution with a $\mathrm{pH}$ value of $4,847 \mathrm{~mL}$ of the acetic acid solution was mixed with $153 \mathrm{~mL}$ of the sodium acetate solution, and the $\mathrm{pH}$ value was measured and adjusted to 4 using $1 \mathrm{M} \mathrm{NaOH}$ solution. To obtain a $\mathrm{pH}$ value of $5.6,95 \mathrm{~mL}$ of the acetic acid solution was mixed with $905 \mathrm{~mL}$ of the sodium acetate solution. The $\mathrm{pH}$ value was measured and adjusted to 5.6.

\subsubsection{Phosphate Buffer Saline (PBS)}

PBS was prepared by dissolving $137 \mathrm{mM} \mathrm{NaCl}, 2.7 \mathrm{mM} \mathrm{KCl}, 10 \mathrm{mM} \mathrm{Na} 2 \mathrm{HPO}_{4}$, and $1.8 \mathrm{mM} \mathrm{KH}_{2} \mathrm{PO}_{4}$ in DDW. The $\mathrm{pH}$ value was measured and adjusted to either 7.4 or 6.5 using a $1 \mathrm{M} \mathrm{HCl}$ solution. 


\subsubsection{Phosphate Buffer (PB)}

Phosphate buffer solution of $0.1 \mathrm{M}$ was prepared using $3.1 \mathrm{~g}$ of $\mathrm{NaH}_{2} \mathrm{PO}_{4}{ }^{*} \mathrm{H}_{2} \mathrm{O}$ and $10.9 \mathrm{~g}$ of $\mathrm{Na}_{2} \mathrm{HPO}_{4}$, which were dissolved in $1 \mathrm{~L}$ of DDW. Following complete dissolving, the $\mathrm{pH}$ was adjusted to 8 using a $5 \mathrm{M} \mathrm{NaOH}$ solution.

\subsection{Synthesis of Acrylated Chitosan}

Acrylated chitosan was synthesized as previously described [18]. Chitosan (1 g) was dissolved in $100 \mathrm{~mL}$ of $2 \%(v / v)$ acetic acid overnight at room temperature, followed by an addition of $1 \mathrm{~g}$ of PEGDA and stirring for $15 \mathrm{~min}$. The reaction mixture was incubated for $3 \mathrm{~h}$ in the dark under shaking at a speed of $100 \mathrm{rpm}$ at $60^{\circ} \mathrm{C}$. The mixture was dialyzed in the dark using a dialysis bag, with a molecular weight cut-off of $12-14 \mathrm{kDa}$ against $5 \mathrm{~L}$ of DDW for three days. After dialysis, the product was filtered with a Buchner funnel, frozen, lyophilized at $0.01 \mathrm{mbar}$ and $-30^{\circ} \mathrm{C}$, and stored at $-20^{\circ} \mathrm{C}$ until further use.

\subsection{Synthesis of Thiolated Pectin}

Thiolated pectin was synthesized using the primary amine groups of the amino acid cysteine, which was covalently anchored to the carboxylic acid groups of pectin. The synthesis was performed according to the procedure previously reported by Majzoob et al. [19] with some modifications.

Pectin of $1 \mathrm{~g}$ was dissolved in $100 \mathrm{~mL}$ of DDW and stirred overnight to form a homogeneous solution. EDAC was added to a final concentration of $50 \mathrm{mM}$, activating the pectin's carboxylic acid groups. The $\mathrm{pH}$ was adjusted to 4.75 using $1 \mathrm{M} \mathrm{NaOH}$ solution, and the reaction was allowed to proceed for $1 \mathrm{~h}$. Then, $2 \mathrm{~g}$ of L-cysteine monohydrate hydrochloride was dissolved in DDW and added at a weight ratio of 2:1 (pectin: cysteine). The $\mathrm{pH}$ was adjusted to 5 , and the mixture was incubated for $24 \mathrm{~h}$ in the dark at room temperature under stirring. The resultant conjugated pectin-cysteine was isolated by dialysis at room temperature in the dark using a cellulose membrane with a $12-14 \mathrm{kDa}$ molecular weight cut-off against $1 \mathrm{mM} \mathrm{HCl}$, twice against $1 \mathrm{mM} \mathrm{HCl}$ containing $1 \% \mathrm{NaCl}$, and finally, once against $1 \mathrm{mM} \mathrm{HCl}$. The polymer solution was frozen, and the material was lyophilized at $-30{ }^{\circ} \mathrm{C}$ and 0.01 mbar and stored at $4{ }^{\circ} \mathrm{C}$ until further use.

The amount of free thiol groups was determined using Ellman's reagent reaction according to the method described in Section 2.8 and was found to be $0.35 \mathrm{mM}$.

\subsection{Hydrogel Fabrication}

Thiolated pectin and acrylated chitosan hydrogels were prepared by mixing the two polymer solutions at different $\mathrm{pH}$ values. A solution of thiolated pectin $(1.33 \%(w / v))$ was dissolved in buffer and stirred overnight. A solution of acrylated chitosan $(1 \%(w / v))$ was dissolved separately in the same buffer and stirred overnight. Subsequently, the two solutions were mixed in pre-determined ratios of thiol to acrylate $(5: 1,3: 1,1: 1,1: 3,1: 5)$ using a vortex and casted into a cylinder mold (14 $\mathrm{mm}$ in diameter and $4 \mathrm{~mm}$ in height) made of Teflon. Gelation was allowed to proceed for different time periods at room temperature in humid conditions.

Gelation was estimated using the vial tilting method, as reported earlier, by flipping the vial and determining whether the mixture flows [12]. A mixture was considered to be in the gel state if there was no flow within $1 \mathrm{~min}$. At the end of the time noted, the vial was tilted again. The mixture was classified as a soft gel if the gel broke and started to flow as a result of the second tilt. The experiments were performed in triplicate.

\subsection{Turbidity Measurements}

Turbidity measurements were performed to indicate the extent of electrostatic interactions between the primary amine of acrylated chitosan and the carboxylic acid in thiolated pectin. Thiolated pectin and acrylated chitosan were separately dissolved in different $\mathrm{pH}$ values, as described in Section 2.5, and mixed. Before curing, the solutions were poured into a 96-well plate and left to cure at room temperature. The absorbance was measured 
using a Synergy ${ }^{\mathrm{TM}}$ HTBioTek ${ }^{\circledR}$ (BioTek Instruments, Winooski, VT, USA) at a wavelength of $380 \mathrm{~nm}$. All samples were compared with the absorbance of thiolated pectin solutions mixed with buffer instead of acrylated chitosan solutions.

\subsection{FTIR}

FTIR spectra were recorded using a Nicolet 6700 FTIR (ThermoScientific, Waltham, MA, USA) coupled to a liquid nitrogen-cooled mercury-cadmium-telluride (MCT) detector in ATR mode. The hydrogel samples were freeze-dried at $0.01 \mathrm{mbar}$ and $-30{ }^{\circ} \mathrm{C}$ and ground to a powder. The spectra were at an average of 128 scans at a resolution of $4 \mathrm{~cm}^{-1}$, and they were corrected for the baseline and smoothed.

\subsection{Free Thiol Group Determination}

The amount of free unreacted thiol groups in the resultant hydrogels was determined using Ellman's reagent reaction, as described by Eshel-Green et al. with modifications [20]. The hydrogels were prepared and casted as described in Section 2.5. Then, the unreacted polymer chains were extracted by submerging the hydrogels in $1.5 \mathrm{~mL}$ DDW for $30 \mathrm{~min}$ in the dark. The tubes were centrifuged using a Megafuge 1.0 centrifuge (Heraeus, Hanau, Germany) at $3300 \mathrm{~g}$ for $5 \mathrm{~min}$. Then, $250 \mu \mathrm{L}$ of the upper liquid containing the unreacted chains was mixed with $2.5 \mathrm{~mL}$ of $\mathrm{PB} \mathrm{pH} 8$ and $50 \mu \mathrm{L}$ of Ellman's reagent $(4 \mathrm{mg} / \mathrm{mL}$ in $\mathrm{PB} \mathrm{pH}$ 8.0) and stirred for $15 \mathrm{~min}$ at room temperature in the dark. Finally, these solutions were poured into a 96-well plate, and the absorbance was measured using a Synergy ${ }^{\mathrm{TM}}$ HTBioTek $^{\circledR}$ (BioTek Instruments, Winooski, VT, USA) at a wavelength of $412 \mathrm{~nm}$. Absorbance readings were taken at time points of 0,72 , and $160 \mathrm{~h}$. The results were analyzed and translated to concentrations using a standard calibration curve of L-cysteine in DDW containing Ellman's reagent solution. The amount of free unreacted thiol groups was calculated from a mass balance.

\subsection{Mechanical Characterization}

Young's modulus was determined from compression assays using a Lloyd mechanical testing machine (AMETEK, Berwyn, PA, USA). Samples were prepared as described in Section 2.5 and compressed at a rate of $1 \mathrm{~mm} / \mathrm{min}$, with a compressive displacement of up to $1.5 \mathrm{~mm}$. Young's modulus was calculated from the linear region of the stress-strain curve, typically up to $10 \%$ strain. Experiments were performed in quadruplicate.

\subsection{Swelling}

Swelling experiments were conducted to determine the swelling ability and the time required for swelling equilibrium. Kinetic experiments were performed in quadruplicate on hydrogels created from solutions with different $\mathrm{pH}$ values and after different curing times. After curing, the hydrogels were placed in a stainless steel grid submerged in a Petri dish containing $50 \mathrm{~mL}$ DDW at room temperature. To minimize water evaporation, the Petri dish was covered during the experiment. Each hydrogel was weighed periodically after wiping excess water with Kimwipes ${ }^{\circledR}$ (Kimberly-Clark ${ }^{\mathrm{TM}}$, Roswell, GA, USA) and returned immediately to the Petri dish. The swelling percentage $\% Q$ at each time interval was determined gravimetrically and calculated as follows:

$$
\% Q=\frac{W_{t}-W_{0}}{W_{0}} \times 100 \%
$$

where $W_{0}$ is the initial weight of the hydrogel, and $W_{t}$ is the weight of the hydrogel at time $t$.

The equilibrium swelling was calculated from the swelling vs. time curve, and the initial weight gain rate, $r$, defined as the slope, was calculated from the linear part of the curve representing the change in $\% Q$ with time. Swelling at equilibrium was estimated from the swelling vs. time curve for each type of hydrogel after $24 \mathrm{~h}$ of swelling. 


\subsection{Small-Angle X-ray Scattering (SAXS)}

SAXS experiments were performed as previously described by Josef et al. [21] using a Molecular Metrology SAXS system equipped with a sealed microfocus tube (MicroMax $-002+S)$ emitting $\mathrm{CuK} \alpha$ radiation. The scattering patterns were recorded by a twodimensional position-sensitive wire detector (Gabriel). The scattered intensity, I(q), was recorded, where $q$ is the scattering vector defined as $q=4 \sin (\theta) / \lambda, 2 \theta$ is the scattering angle, and $\lambda$ is the incident wavelength. After preparing the hydrogels, they were immediately poured into a thin-walled glass capillary (diameter of $2 \mathrm{~mm}$ and wall thickness of $0.01 \mathrm{~mm}$ ) and sealed. SAXS measurements were recorded at time points of 0,72 , and $160 \mathrm{~h}$.

\subsection{Texture Profile Analysis (TPA)}

The TPA of the hydrogels (height of $15 \mathrm{~mm}$, diameter of $26 \mathrm{~mm}$ ) was carried out using a Lloyd textile profile TA1 texture analyzer (AMETEK, Berwyn, PA, USA) equipped with a $10 \mathrm{~N}$ load cell. The analysis protocol consists of a two-cycle compression test to a maximum deformation of $50 \%$ between two parallel plates. The hydrogels were compressed at a rate of $30 \mathrm{~mm} / \mathrm{min}$ at room temperature. The adhesive force, adhesiveness, and hardness were obtained from the texture profile and analyzed. Five samples were measured for each formulation.

\subsection{Statistical Analysis}

Statistical analysis was performed using Microsoft Excel software. Data from independent experiments were quantified and analyzed for each variable. Comparisons between multiple treatments were made with analysis of variance (ANOVA), and adhoc comparisons between two treatments were made using a two-tail Student's $t$-test. A $p$-value of $<0.05$ was considered statistically significant. Standard errors of the mean were calculated and presented for each treatment group.

\section{Results and Discussion}

\subsection{Conditions of Hydrogel Formation}

The hydrogels investigated in this study contained two polymers: acrylated chitosan and thiolated pectin. We anticipated that dual cross-linking could exist in this system: one arising from electrostatic interactions between the positively charged amine in chitosan and the negatively charged carboxylic acid on pectin, and the other from the chemical Michael-type addition reaction between thiol and acrylate. As the reaction kinetics between thiol and acrylates is known to be slow [17], the gelation process was studied over time.

To screen different formulations, we mixed a solution of thiolated pectin with a second solution of acrylated chitosan at room temperature and applied the tilt method to classify the mixture as a solution, a soft gel, a gel, or a hard gel (Figure 1). Different thiol-to-acrylate ratios and various total concentrations were studied, keeping the $\mathrm{pH}$ value constant using the acetate buffer at $\mathrm{pH}$ 5.6. This $\mathrm{pH}$ value was chosen following the results presented in a previous study by Marudova et al. [11], where the gelation of chitosan and pectin was studied. Chitosan was found to function as an effective crosslinker of pectin with a relatively low degree of esterification of $36 \%$. The gelation process was initiated spontaneously upon mixing the two solutions. Raising the temperature to $37^{\circ} \mathrm{C}$ had no effect on the curing time (data not shown). As shown in Figure $1 \mathrm{~b}-\mathrm{d}$, mixtures with a total concentration lower than $0.4 \%$ did not form hydrogels, regardless of the thiol-to-acrylate ratio, probably because the concentration of the polymer chains was too low to create enough entanglements to form a three-dimensional matrix. This result did not change at longer gelation times. After $72 \mathrm{~h}$ of cross-linking, the gelation ability relied on both the thiol-to-acrylate ratio and the concentration. When the thiols were in excess, increasing the total concentration resulted in a transition from a solution to a soft gel (Figure 1b), whereas a further increase in concentration led to the formation of a hard gel. The solution to soft gel transition concentration and the soft gel to hard gel transition concentration seemed to decrease when the thiol excess decreased. Excess acrylate impaired the gelation ability, 
and the mixtures exhibited properties of a solution even when the total concentration was increased. Only at a high total concentration of $1.75 \%$ did the polymer mixture exhibit properties of a gel. Figure $1 \mathrm{c}$ shows the phase diagram after $120 \mathrm{~h}$ of curing and presents a similar trend compared with $72 \mathrm{~h}$ of curing. An exception was the formulations with a high thiol-to-acrylate ratio at a total concentration of $1.25 \%$. These formulations were classified as soft gels after $72 \mathrm{~h}$ of curing but turned into gels after $120 \mathrm{~h}$. This trend of soft gels, which became firmer and harder, was even more pronounced in the phase diagram for hydrogels that were left to cure for $160 \mathrm{~h}$, as presented in Figure 1d.

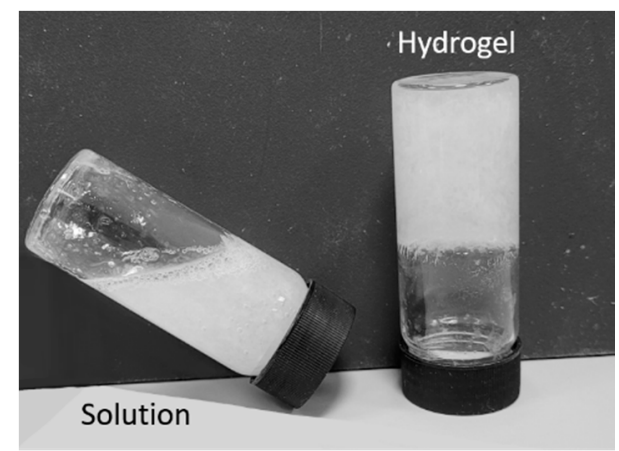

(a)

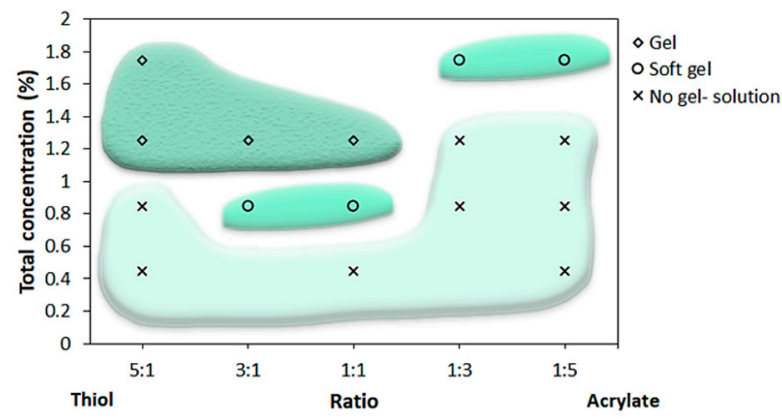

(c)

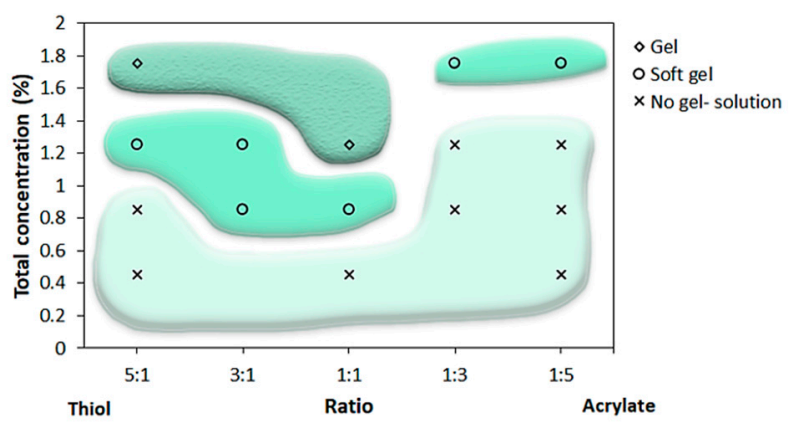

(b)

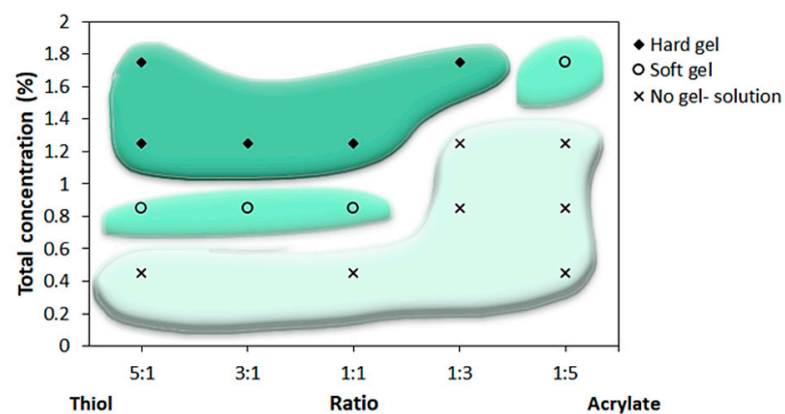

(d)

Figure 1. (a) The vial tilting method representing a "solution" phase and a "hard gel" phase. Phase diagram of the pectin-thiol and chitosan-acrylate hydrogels in a fixed $\mathrm{pH}$ value of 5.6 after curing for (b) 72, (c) 120, and (d) $160 \mathrm{~h}$. $n=3$.

Figure 1 also shows that hydrogels prepared with a high thiol-to-acrylate ratio transformed from soft gels to gels and hard gels with time, indicating that the cross-linking was a slow process. These findings are consistent with those of previous studies on poly (ethylene glycol) (PEG)-based hydrogels formed using the Michael-type addition reaction between thiol and acrylate. This reaction has a step-growth polymerization mechanism, which is known to have a slow polymerization rate $[17,22]$.

\subsection{Interaction between Acrylated Chitosan and Thiolated Pectin}

Following the results presented in the previous section, a ratio of 5:1 thiol to acrylate and a total concentration of $1.25 \%$ were chosen for further investigations. This formulation seems to be the most interesting since it showed intermediate properties of a soft gel $72 \mathrm{~h}$ after curing, and further displayed evolution with time from soft gels to gels and finally to hard gels. Thus, we investigated the changes in the properties depending on the curing time. The effect of $\mathrm{pH}$, which is known to play a key role in polyelectrolyte complex formation, was also analyzed because it affects the degree of ionization of the functional groups. 


\subsubsection{Electrostatic Interactions}

Electrostatic interactions between the carboxylic acid of pectin and the amine group of chitosan can be generated at $\mathrm{pH}$ values between 3 and 6 , which are above the $\mathrm{pKa}$ of pectin but below the pKa of chitosan [11,23,24]. However, in this hybrid system, the bulky side groups of PEGDA carried by chitosan could interfere with the complex formation. Therefore, we were interested in charactering the extent of electrostatic interactions in the hydrogel matrix. The use of turbidity measurements allowed for the examination of the extent of the polyelectrolyte complexation. A similar methodology was previously used to evaluate the magnitude of electrostatic interactions between cationized gelatin and gum arabic [25] and the formation of gelatin and the k-carrageenan complex [26]. Figure 2a shows that the hydrogels prepared from thiolated pectin and acrylated chitosan had high turbidity values compared with the transparent control solutions made of only thiolated pectin and buffer. The hydrogels prepared at $\mathrm{pH} 4$ had the highest turbidity value (Figure 2a). Furthermore, the turbidity of thiolated pectin and acrylated chitosan hydrogels was found to be significantly $\mathrm{pH}$ dependent (ANOVA, $p<0.05$ ), and that of the control was almost constant. Turbidity was also examined at different gelation times, but its value was constant with time (ANOVA, $p>0.5$, Figure $2 b$ ).

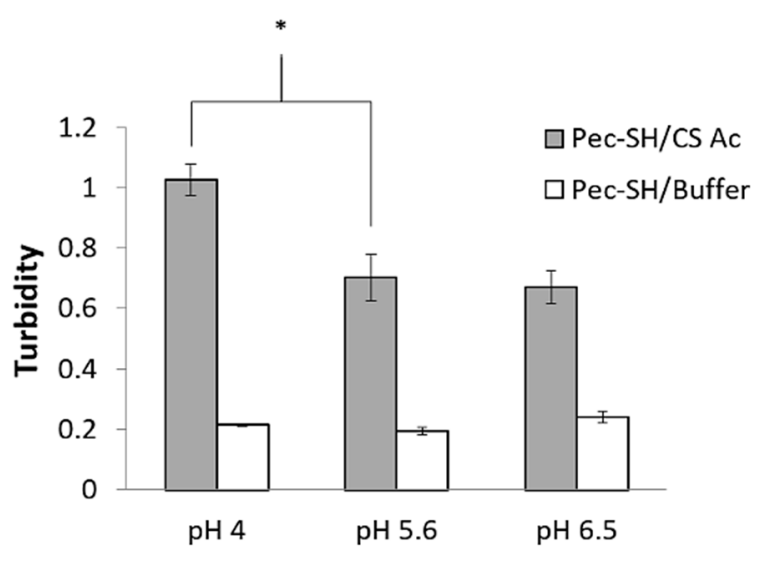

(a)

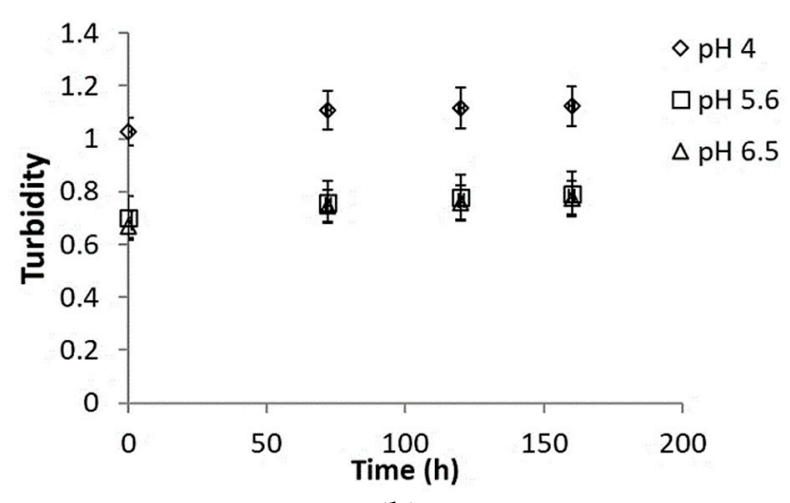

(b)

Figure 2. Turbidity measurements of hydrogels prepared at different $\mathrm{pH}$ values. (a) Immediately after mixing and casting. (b) Change with time. The bars represent the standard error of the mean, $n=3$. $\left(^{*}\right)$ refers to a statistically significant difference at $p<0.05$.

The high turbidity at $\mathrm{pH} 4$ is attributed to the complex formation. This indicates that the strong electrostatic interactions between the negatively charged carboxylate groups of pectin and the positively charged amino groups of chitosan $[5,27]$ are not hampered due to acrylation or thiolation. The increase in $\mathrm{pH}$ causes deprotonation of the amine groups present in chitosan, resulting in a reduction of the net charge in the gel. This eventually leads to depletion in the pectin-chitosan interactions. Higher $\mathrm{pH}$ values promote other reactions, such as the Michael-type addition and formation of disulfide bonds $[14,28]$. The constant turbidity with time suggests that the rate of reaction in the case of electrostatic interactions is very fast, causing turbidity to form instantly. Moreover, it shows that other interactions that participate in hydrogel formation do not affect turbidity values.

\subsubsection{Chemical Reaction}

The Michael-type addition reaction between pectin thiol and chitosan acrylate was verified by analyzing the FTIR spectra. The FTIR spectra of the hydrogels obtained after $72 \mathrm{~h}$ of cross-linking at different $\mathrm{pH}$ values are shown in Figure 3. Two typical peaks attributed to the presence of PEGDA are seen between 1800 and $1600 \mathrm{~cm}^{-1}$ (stretching vibration of ester) and $800 \mathrm{~cm}^{-1}$ (stretching vibration of $C=C$ ) [29]. 


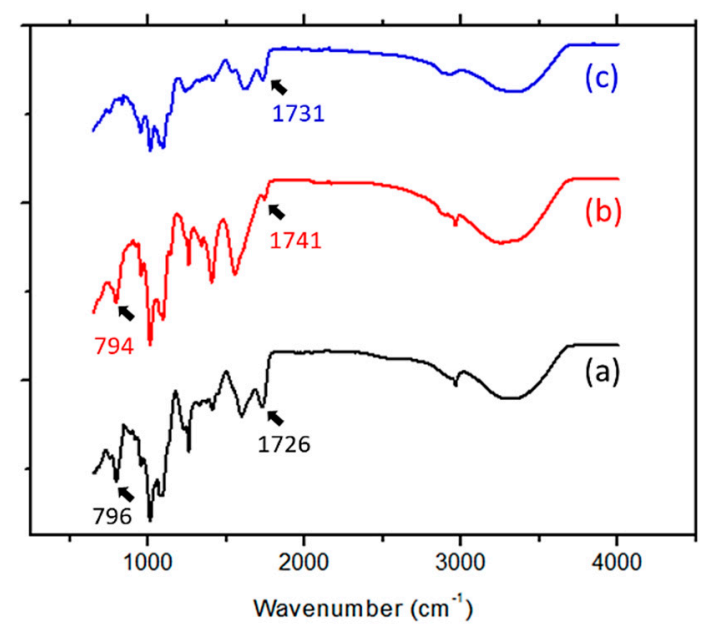

Figure 3. FTIR analysis of hydrogels prepared at (a) $\mathrm{pH} 4$, (b) $\mathrm{pH} 5.6$ and (c) pH 6.5.

The spectra from the hydrogels prepared at $\mathrm{pH} 4$ and $\mathrm{pH} 5.6$ presented two typical peaks, indicating that some acrylate groups remained unattached. However, in the spectra of the hydrogels prepared at $\mathrm{pH} 6.5$, the stretching vibration peak of the $\mathrm{C}=\mathrm{C}$ group at $800 \mathrm{~cm}^{-1}$ disappeared. These observations suggest that the Michael-type addition reaction at low $\mathrm{pH}$ was not fully completed, whereas the acrylate groups were consumed by this reaction at a high $\mathrm{pH}$ value of 6.5 after $72 \mathrm{~h}$.

To better understand the reaction mechanism, a kinetic study was performed by monitoring the amount of free thiols in the hydrogels at predetermined gelation times [30]. As shown in Figure 4, the initial concentration of free thiols was low for $\mathrm{pH} 6.5$ compared with other $\mathrm{pH}$ values. At this $\mathrm{pH}$ value, disulfide bonds are typically generated. YomTov et al. showed that the extent of disulfide bond formation could affect the hydrogel properties in a cross-linked hydrogel system composed of PEG-4SH and PEGDA [17]. They demonstrated that a network of tetra-PEG is obtained by forming disulfide bonds in a solution upon mixing. Since the polymerization reaction had already been started during the reagent's separate mixing, the formation of the final network resulted in a faster gelation rate once PEG-4SH networks were combined with PEGDA solutions. Pectin is a highly branched polysaccharide capable of self-gelation at acidic $\mathrm{pH}$ [31]. The addition of thiol groups to this polymer allows for self-gelation at high $\mathrm{pH}$ values via disulfide bridges [28]. Thus, the data presented in Figure 4 imply that, at a high $\mathrm{pH}$ value, a preliminary network composed of disulfide bonds is created during the reagents' separate mixing phase. Taking these results together with the ones in Figure 1, we hypothesize that a preliminary network must be formed to create a stable gel. Therefore, when the thiol-to-acrylate ratio is low, a gel state is not formed, probably because there are not enough thiols to create the preliminary network. The free thiol concentration decreased after $72 \mathrm{~h}$ of cross-linking for all the examined $\mathrm{pH}$ values and reached a plateau, as it was not changed further statistically after $160 \mathrm{~h}(p>0.5$, Figure 4). These results support the claim that, in this hydrogel system, the Michael-type addition reaction is very slow.

\subsection{Mechanical Characterization}

The stiffness of the hydrogels, described as Young's modulus, was evaluated as a function of time and $\mathrm{pH}$ value (Figure 5). An increase in the modulus as a function of the $\mathrm{pH}$ was observed for all the examined gelation periods. After $72 \mathrm{~h}$ of cross-linking, increasing the $\mathrm{pH}$ from 4 to 5.6 resulted in a significant increase in the modulus from 1.2 to $2.5 \mathrm{kPa}(p<0.01)$. A further increase in $\mathrm{pH}$ from 5.6 to 6.5 caused a further increase in the modulus from 2.5 to $3.2 \mathrm{kPa}(p<0.0001)$. After $120 \mathrm{~h}$ of cross-linking, an increase in the modulus value was detected when the $\mathrm{pH}$ value increased from 4 to $5.6(p<0.0001)$. However, a further increase in modulus was not obtained after a further increase to $\mathrm{pH}$ 6.5. A similar trend was observed in a longer gelation period of $160 \mathrm{~h}(p<0.005)$. Figure $5 \mathrm{~b}$ 
shows the relationship between the modulus and the gelation time. At $\mathrm{pH} 4$, the modulus was constant and did not change with the increase in gelation time. However, at higher $\mathrm{pH}$ values, the modulus increased when the gelation was allowed to proceed for longer times.

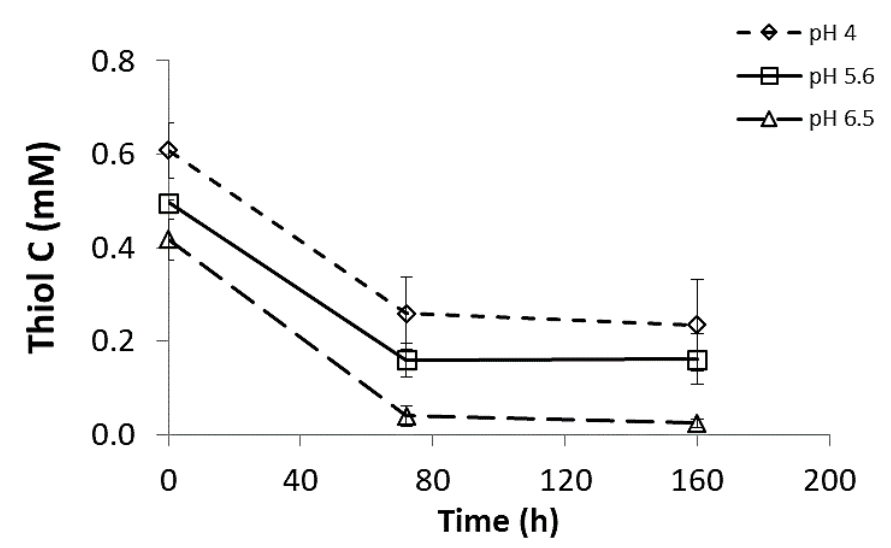

Figure 4. Kinetic analysis was performed using Ellman's reagent representing the thiol concentration in gel vs. time. The bars represent the standard error of the mean, $n=3$.

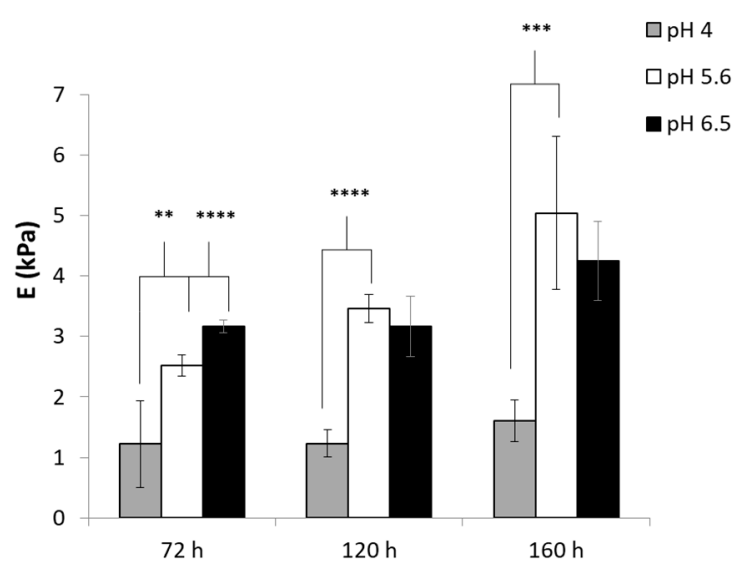

(a)

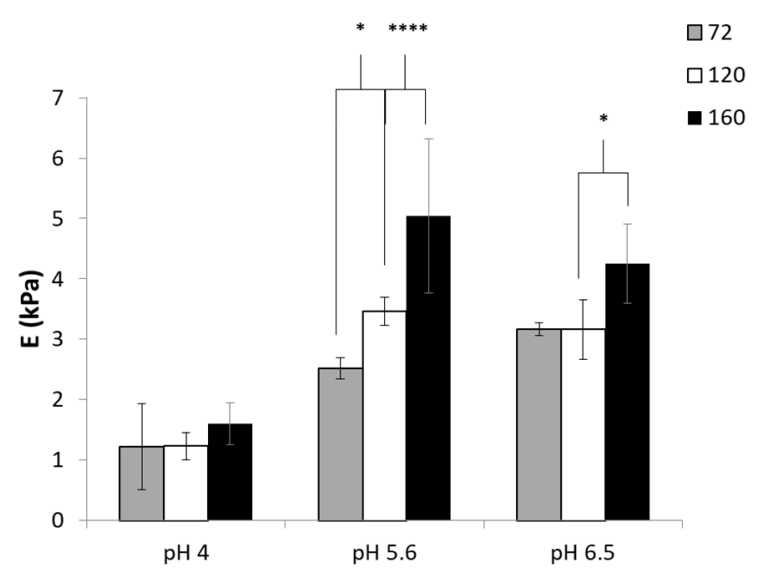

(b)

Figure 5. Young's modulus of the pectin thiol and chitosan acrylate hydrogels (a) vs. gelation time and (b) vs. $\mathrm{pH}$ value during preparation. The bars represent the standard error of the mean, $n=5$. $\left({ }^{*}\right)$ refers to a statistically significant difference at $p<0.05,\left(^{* *}\right)$ refers to a statistically significant difference at $p<0.01,\left({ }^{* *}\right)$ refers to a statistically significant difference at $p<0.005$, and $\left(^{* * *}\right)$ refers to a statistically significant difference at $p<0.0001$.

As the chemical composition and the polymer concentration are identical for all studied samples, the stiffness of the hydrogels was determined by their degree of crosslinking. Electrostatic interactions lead to a complex formation, which acts as physical cross-links. These interactions were formed between the positive amine group of acrylated chitosan and the negative carboxylic acid of thiolated pectin. Our turbidity measurements demonstrated that the magnitude of the electrostatic interactions was favorable at $\mathrm{pH} 4$ and diminished at pH 5.6 and 6.5. The covalent bonds were established by the Michaeltype addition reaction between the acrylate conjugated to chitosan and the thiol group in thiolated pectin. This thiol-ene click chemistry was triggered by the thiolate anion, which acts as a nucleophile and attacks the carbon of the alkene $[14,16]$. The number of thiolate anions also depends on the $\mathrm{pH}$ of the solution; the reaction is favorable when the $\mathrm{pH}$ values are high [32]. Our FTIR and thiol content results show that the extent of chemical reaction increased with $\mathrm{pH}$. Thus, as the $\mathrm{pH}$ increased, electrostatic interactions became less prominent, whereas the extent of chemical links was enhanced. Therefore, 
the strengthening of the mechanical characteristics with the increase in $\mathrm{pH}$ indicates that covalent bonds are more significant than electrostatic interactions in determining the stiffness of the hydrogels.

In comparing the results after different gelation periods, the stiffness increased at times longer than $72 \mathrm{~h}$ only at $\mathrm{pH}$ values of 5.6 and 6.5 , suggesting that the cross-linking density increased. As was mentioned earlier, previous studies have shown that the Michaeltype addition reaction between thiol and acrylate has slow kinetics [15]. Yom-Tov et al. evaluated the mechanical characteristics of PEG-thiol and PEGDA cross-linked hydrogels with a curing time of up to 7 days [17]. Our observations support this conclusion, indicating that a slow gelation mechanism is involved mainly at high $\mathrm{pH}$ values.

To conclude, by extending the gelation time and/or the $\mathrm{pH}$ value of the polymers, the reaction conversion may be improved, and better mechanical properties can be obtained.

The results in this section demonstrate that, for the studied samples, the properties of hydrogels changed significantly between curing times of 72 and $160 \mathrm{~h}$. Therefore, these curing times were chosen for further examination.

\subsection{Effect of $\mathrm{pH}$ on Swelling Capacity}

As swelling ability is one of the most important characteristics of hydrogels, the effect of $\mathrm{pH}$ value and gelation time on swelling was examined (Figure 6). An increase in curing time from $72 \mathrm{~h}$ to $160 \mathrm{~h}$ led to a significant decrease in swelling ability for all the examined $\mathrm{pH}$ values (Figure 6a). The hydrogels prepared at $\mathrm{pH} 4$ showed an equilibrium swelling of $350 \%$ after $72 \mathrm{~h}$ of cross-linking and after $160 \mathrm{~h}$ they displayed a swelling ability of $250 \%(p<0.05)$. The same trend was observed for $\mathrm{pH} 5.6$ and 6.5 in which the equilibrium swelling decreased from $240 \%$ to $180 \%(p<0.05)$ and from $190 \%$ to $140 \%$ $(p<0.05)$, respectively. The water uptake of the hydrogels in equilibrium was found to be significantly $\mathrm{pH}$ dependent for both of the examined gelation periods (ANOVA, $72 \mathrm{~h}$ $p<0.01, n>3,160$ h $p<0.0005, n>3$ ).

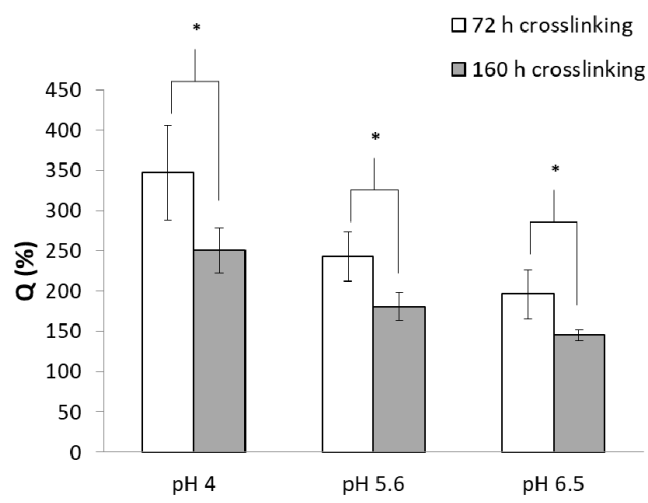

(a)

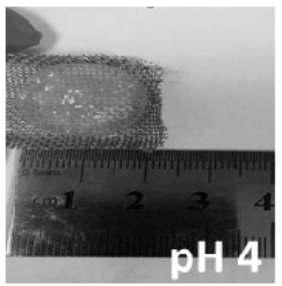

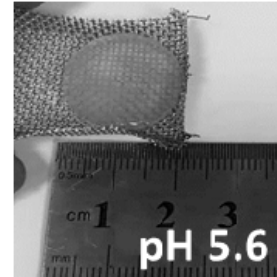

(c)

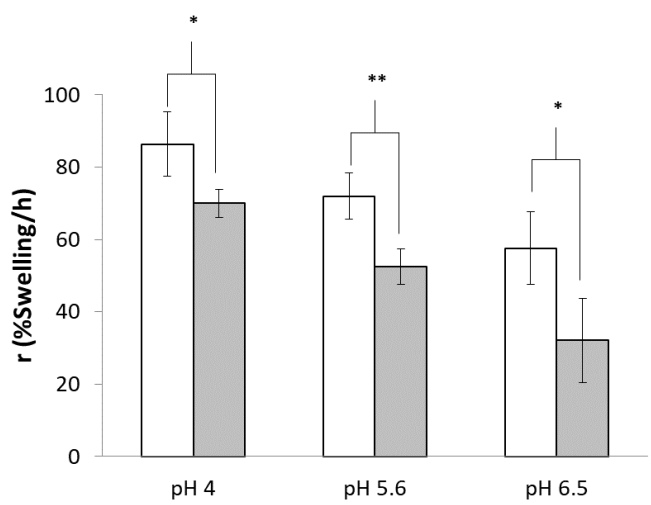

(b)

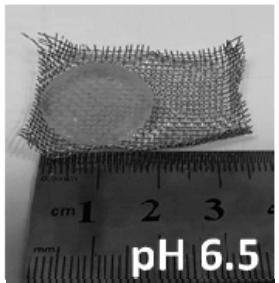

pH 6.5

Figure 6. (a) Q-Swelling in equilibrium and (b) initial water gain rate vs. pH value during preparation. (c) Swollen hydrogels cross-linked for $160 \mathrm{~h}$. The bars represent the standard error of the mean, $n=4$. $\left(^{*}\right)$ refers to a statistically significant difference of $p<0.05$, and $\left.{ }^{* *}\right)$ refers to a statistically significant difference of $p<0.01$. 
Figure $6 \mathrm{~b}$ illustrates the swelling rate of the hydrogels calculated from the slope of the linear part of the swelling vs. time curves. Hydrogels cured for $72 \mathrm{~h}$ swelled faster than those cured for $160 \mathrm{~h}$. The rate of swelling was found to be significantly $\mathrm{pH}$ dependent (ANOVA, $72 \mathrm{~h} p<0.05, n>3,160 \mathrm{~h} p<0.0005, n>3$ ), indicating that as the $\mathrm{pH}$ value increased, the rate of swelling decreased.

Figure $6 \mathrm{c}$ demonstrates that hydrogels fabricated at various $\mathrm{pH}$ values and crosslinked for $160 \mathrm{~h}$ differ in their swelling ability.

The greater swelling ability and faster swelling rate of hydrogels cured for a shorter gelation time indicate a lower cross-linking density [17]. Further, an inverse correlation between Young's modulus values and swelling behavior was well established in previous studies [33].

The increase in $\mathrm{pH}$ affected the swelling behavior, consistent with our previous suggestion that as the $\mathrm{pH}$ increases, the Michael-type addition reaction becomes more favorable. A high reaction conversion increased the cross-linking density, which decreased the swelling ability and swelling rate.

\subsection{Nanostructure Examination Using SAXS}

The inhomogeneities in the hydrogels led us to hypothesize that the nanometric structure could change with time and $\mathrm{pH}$. Thus, we gathered information related to the hydrogel structure using SAXS.

The SAXS patterns of hydrogels at different $\mathrm{pH}$ values immediately after mixing are presented in Figure 7a. The results show no apparent difference at large scattering angles as the plots overlap. At smaller scattering angles, the curves became sensitive to the $\mathrm{pH}$ of the hydrogel. The change in the shape of the curve, particularly the appearance of a shoulder at the intermediate $\mathrm{pH}$ value, suggests that the scattering curve reflects a superposition of two contributions: one arising from the polymer network that dominates mainly at high scattering angles and the other from the formation of aggregates that dominate at small angles.

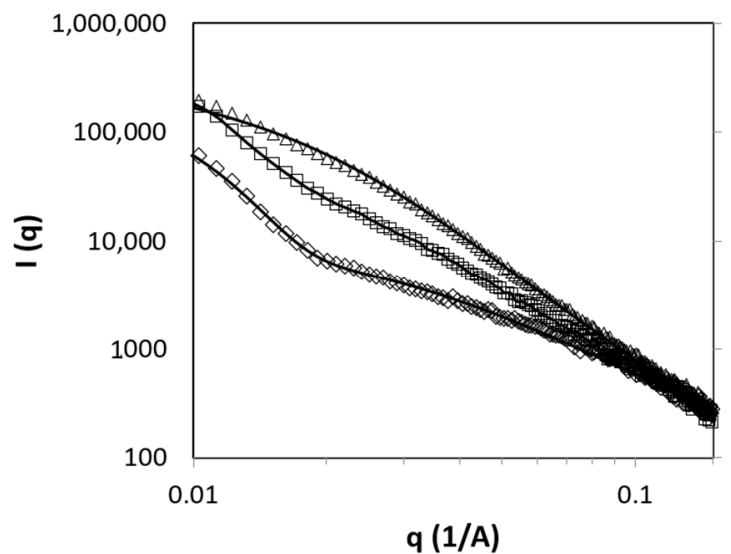

(a)
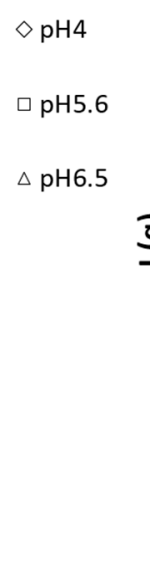

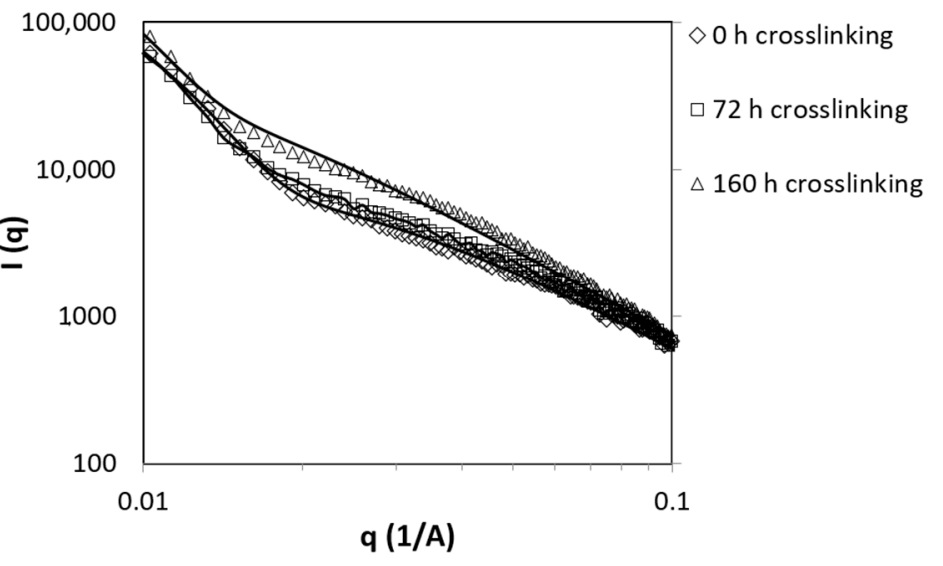

(b)

Figure 7. SAXS curves of hydrogels (a) at different $\mathrm{pH}$ values immediately after mixing and (b) at $\mathrm{pH} 4$ at different curing times. Lines represent the fit to the aggregate and network model (Equation (2)) for pH 5.6 and pH 6.5, and Equation (3) for $\mathrm{pH} 4$.

We attempted to fit the SAXS plots to two models describing inhomogeneous hydrogels. The first model is the classical Ornstein-Zernike model with a Debye-Bueche term, which is commonly used to describe hydrogels [34,35]. The form factor $P(q)$ is represented by

$$
P(q)=\left(\frac{k_{n e t}}{1+\left(q \xi_{n e t}\right)^{2}}\right)+\left(\frac{k_{a g g}}{\left(1+\left(q \xi_{a g g}\right)^{2}\right)^{2}}\right)
$$


where $\xi_{\text {net }}$ is the correlation length of the network, $\xi_{\text {agg }}$ is the dimension of aggregates, $k_{n e t}$ is the constant of the network, and $k_{\text {agg }}$ is the constant of the aggregates.

The second model was previously used to describe inhomogeneous polyacrylamide hydrogels [36].

$$
P(q)=\left(\frac{k_{\text {net }}}{\left(1+\left(q \xi_{\text {net }}\right)^{2}\right)^{1 / 2}}\right)+k_{\text {agg }} \exp \left(-\frac{1}{3}+\left(q R_{\text {agg }}\right)^{2}\right)
$$

where $\xi_{\text {net }}$ is the correlation length of the network, $R_{a g g}$ is the dimension of aggregates, $k_{n e t}$ is the constant of the network, and $k_{a g g}$ is the constant of the aggregates.

Equation (2) shows a good fit to the scattering from hydrogels prepared at $\mathrm{pH} 6.5$ and as well as $\mathrm{pH}$ 5.6, while a better fit for $\mathrm{pH} 4$ was obtained with Equation (3). The parameters calculated from the fitting are presented in Table 1 . The results suggest that the increase in the degree of inhomogeneity with $\mathrm{pH}$ was caused by the increase in the number of aggregates. The increase in mesh size with $\mathrm{pH}$ can also be attributed to enhanced aggregation. Fewer chains are available for the creation of the network as they form the aggregates. The aggregates contribute to the cross-linked network, and thus the swelling degree decreases as the curing time increases (Figure 6a).

Table 1. Parameters derived from fitting the scattering curves of hydrogels at different $\mathrm{pH}$ values and curing times.

\begin{tabular}{cccccc}
\hline & Time [h] & $\xi_{\text {net }}[\AA$ [̊] & $\boldsymbol{R}_{\text {agg }}[\AA \AA$ [ $]$ & $\boldsymbol{k}_{\text {net }}$ & $\boldsymbol{k}_{\text {agg }}$ \\
\hline \multirow{2}{*}{ pH 4 } & 0 & 38.2 & 208.4 & 9314.7 & $225,747.1$ \\
& 72 & 41.4 & 225.0 & $12,193.3$ & $269,394.3$ \\
& 160 & 87.7 & 274.7 & $57,456.9$ & $632,203.7$ \\
\hline \multirow{2}{*}{ pH 5.6 } & 0 & & & & \\
& 72 & 265.8 & 99.8 & $538,136.6$ & $291,854.0$ \\
& 160 & & & & $254,269.9$ \\
\hline \multirow{2}{*}{ pH 6.5 } & 0 & & & & \\
& 72 & 327.1 & 47.8 & $521,801.3$ & $184,615.5$ \\
& 160 & & & & $237,117.1$ \\
\hline
\end{tabular}

Figure $7 \mathrm{~b}$ shows the change in the scattering curve with the increase in curing time for $\mathrm{pH}$ 4. At this $\mathrm{pH}$, the hydrogels presented an increase in the mesh size of the net ( $\left.\xi_{\text {net }}\right)$ with time (Table 1 ). The characteristic size of the aggregates, $R_{a g g}$, also increased simultaneously. The parameter $k_{a g g}$, which represents the amount of aggregates, increased with time, while the parameter $k_{\text {net }}$ decreased (Table 1$)$. Thus, similar to the effect of $\mathrm{pH}$, increasing the curing time at $\mathrm{pH} 4$ led to aggregation. For hydrogels prepared at $\mathrm{pH} 5.6$ and $\mathrm{pH} 6.5$, the scattering curve did not change with time (data not shown).

We can conclude that the structure of hydrogels may be inhomogeneous and composed of a gel matrix with a mesh size that decreases over time and heterogeneous clustered regions that may function as cross-linking spots. This increase in heterogeneous regions may be a result of the Michael-type addition reaction at a long curing time, which is less favorable at a low $\mathrm{pH}$ value.

\subsection{TPA Measurements}

While performing the experiments, we observed that the hydrogels adhered to different surfaces. To quantify the adhesiveness, we used texture analysis, which is a common technique employed in the industry for the mechanical characterization and evaluation of food textural behavior [37]. It was previously used as a method for pharmaceutical gel characterization [38].

Figure 8a illustrates the force-deformation curves of hydrogels cross-linked for $160 \mathrm{~h}$ and prepared at three different $\mathrm{pH}$ values. After the first compression, the three hy- 
drogels presented a negative area associated with the adhesiveness property of the gel (Figure 8a). The hardness of the hydrogels increased significantly with the increase in $\mathrm{pH}$ from $0.88 \pm 0.25 \mathrm{~N}$ for $\mathrm{pH} 4$ to $2.15 \pm 0.39 \mathrm{~N}$ for $\mathrm{pH} 6.5$ (ANOVA, $p<0.005$, Figure $8 \mathrm{~b}$ ).

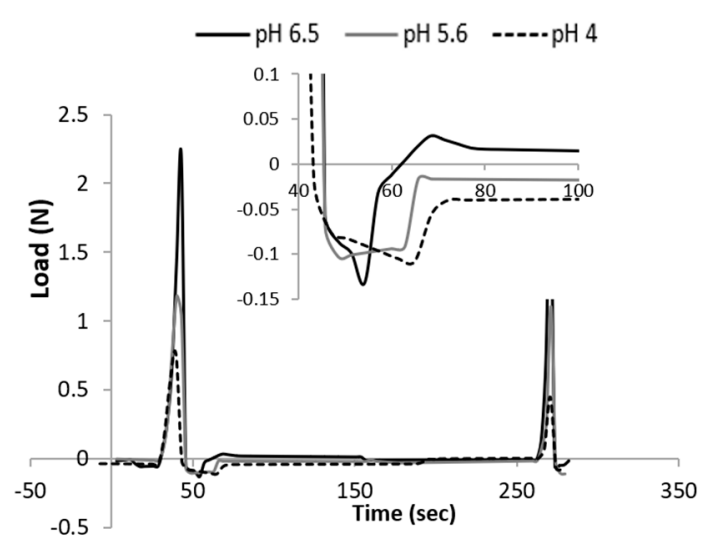

(a)

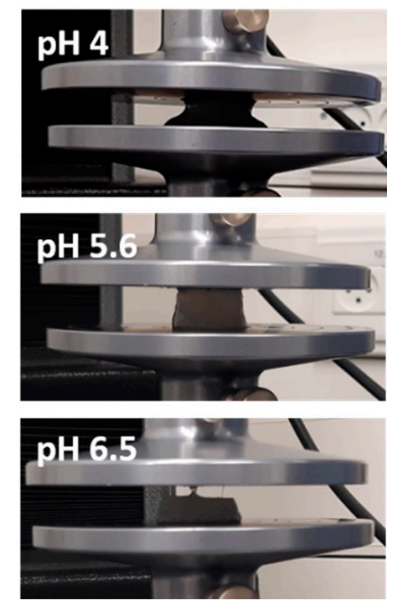

(c)

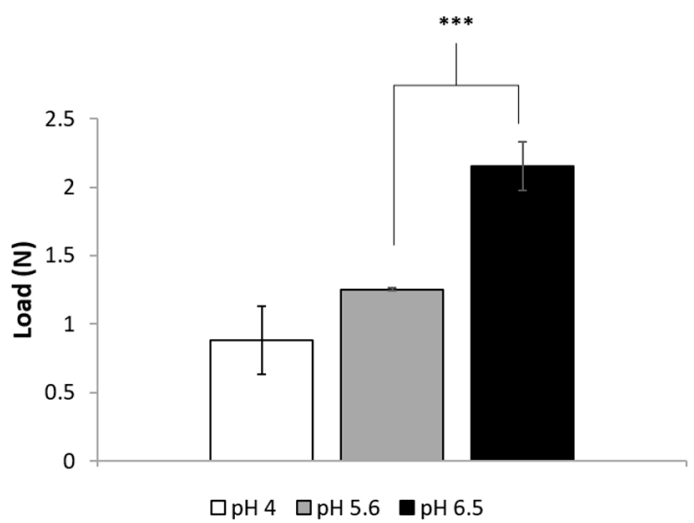

(b)

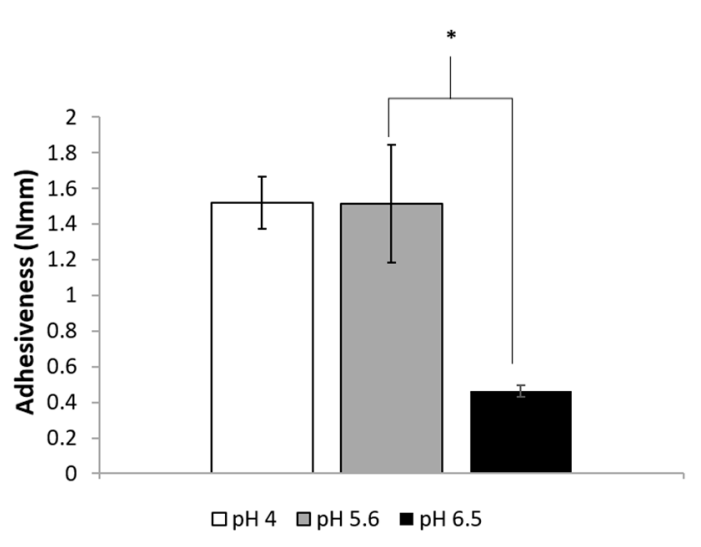

(d)

Figure 8. Texture profile analysis experiment. (a) Force-deformation curves, (b) hardness (ANOVA $p<0.005$ ), (c) qualitative observation of the adhesiveness, and (d) adhesiveness (ANOVA, $p<0.05$ ) of hydrogels cross-linked for $160 \mathrm{~h}$ and prepared at three different $\mathrm{pH}$ values. The bars represent the standard error of the mean, $n=5$. ${ }^{*}$ ) refers to a statistically significant difference of $p<0.05$, and $\left(^{* * *}\right)$ refers to a statistically significant difference of $p<0.005$.

A large difference was observed qualitatively between hydrogels prepared at different $\mathrm{pH}$ values and similar curing times (Figure $8 \mathrm{c}$ ). The hydrogels prepared at $\mathrm{pH}$ values under the pKa of chitosan were sticky and adhered to the upper plate, whereas those prepared at $\mathrm{pH} 6.5$ were not and did not. Figure 8c shows the adhesiveness of the hydrogels measured as the negative work between the two cycles. The results support the qualitative observation: the adhesiveness of the hydrogels was high at low $\mathrm{pH}$ values and decreased statistically at $\mathrm{pH} 6.5$ (ANOVA, $p<0.05$, Figure $8 \mathrm{~d}$ ).

Figure 8 shows that high adhesiveness is associated with hydrogels prepared at low $\mathrm{pH}$ values. Our previous experiments revealed that, under these conditions, the thiol concentration in the hydrogel is high. Unattached thiol groups are known to present adhesive properties that are exploited in many fields, such as semiconductors [39], sticky surfaces [40,41], and bioadhesion [42]. This chemical group can bind different molecules. For example, in the field of mucoadhesion, thiols can form disulfide bonds with glycoproteins, which are secreted by the mucosal tissue. Therefore, it is reasonable to assume that the free thiol groups on the hydrogel surface are responsible for the adhesion properties. 
Hydrogels prepared using a $\mathrm{pH} 6.5$ buffer presented a low concentration of free thiols, thus showing low adhesiveness in the TPA assay (Figure 8c,d).

The upper plate of the texture analyzer device is composed of aluminum, which is also known to bind thiols [43].

The adhesive properties of the novel acrylated chitosan/thiolated pectin hydrogels may open the possibility of their use as mucosal mimetic surfaces. Mucoadhesion is the term describing the ability of a material to adhere to mucosal surfaces [44]. This field has attracted much attention in the past few decades, as mucoadhesive materials increase the residence time of drugs at the application site [45-47]. Early stages in the development of novel mucoadhesive systems require the utilization of animal tissues for adhesion testing. However, experiments performed on ex vivo tissues may lead to unreliable results due to technical limitations, such as the large variance between animals. In addition, the will to avoid animal killing raises the need for alternative substrates. Recently, several synthetic model surfaces have been developed in an attempt to mimic mucus layer properties [48-50]. Thiolated pectin hydrogels were previously studied by Dozli et al., who claimed that the hydrogels combine all the main features of the mucosa (gellike character, negative charge, sugar moieties and free thiol groups) in one substrate [51]. They explained that this may increase the similarity to the mucosa and thus improved the substrate's performance. Another feature not discussed in the literature with respect to mucosal mimetic surfaces is the $\mathrm{pH}$. Different mucosal membranes in the body have different $\mathrm{pH}$ values; for example, the $\mathrm{pH}$ in the vagina is 4 [52], while its value in the nose or intestine is between 5.5 and 6.5 [53]. The $\mathrm{pH}$ of the mucosal surface is crucial for the accurate examination of mucoadhesive formulations. Therefore, the hydrogel system presented in this research, which is similar to the one described by Dozli et al., could demonstrate another characteristic in its physical resemblance to natural mucosal tissue. Further studies could confirm that this hydrogel system could be used as a mimetic, with high similarity to the mucosa of various regions in the body.

\section{Conclusions}

A novel hydrogel system based on the physical and chemical interactions between thiolated pectin and acrylated chitosan was developed and characterized. This hybrid system was found to show different properties when gelation was conducted at different $\mathrm{pH}$ values and curing times. Turbidity measurements revealed that at low $\mathrm{pH}$ values below the pKa of chitosan, more electrostatic interactions were formed between opposite charges. However, at high $\mathrm{pH}$ values, the FTIR results showed the occurrence of the Michael-type addition reaction between the acrylate and thiol. Mechanical characterization demonstrated that increasing the $\mathrm{pH}$ value created stiffer hydrogels. SAXS measurements revealed that the nanostructure of the hydrogels was inhomogeneous and composed of a gel matrix with a mesh size that decreases over time and heterogeneous clustered regions, which could function as cross-linking spots. The texture profile analysis assay showed that hydrogels prepared at a $\mathrm{pH}$ below the $\mathrm{pKa}$ of chitosan had greater adhesiveness, and this property was attributed to the free thiol groups in the gel. The hybrid hydrogel system has controllable properties and can be applied to develop tailor-made biomaterials for specific applications. It could be a good candidate for a wide range of biomedical applications, such as substrates for mucosa-mimetic materials, which have a greater resemblance to the natural mucosal tissue of various regions in the body.

Author Contributions: S.E. and H.B.-P. conceived and designed the experiments; S.E., A.G., and E.R. performed the experiments and analyzed the data; and S.E. and H.B.-P. wrote the paper. All authors have read and agreed to the published version of the manuscript.

Funding: This research received no external funding.

Institutional Review Board Statement: Not applicable.

Informed Consent Statement: Not applicable. 
Data Availability Statement: The data presented in this study are available on request from the corresponding author.

Acknowledgments: The authors would like to thank Maya Davidovich-Pinhas and Daniel Golodnizky for their support in the texture profile analysis experiments and Rafail Khalfin and Elinor Josef for their assistance in the SAXS measurements and data analysis.

Conflicts of Interest: The authors declare no conflict of interest.

\section{References}

1. Tu, Y.; Chen, N.; Li, C.; Liu, H.; Zhu, R.; Chen, S.; Xiao, Q.; Liu, J.; Ramakrishna, S.; He, L. Advances in injectable self-healing biomedical hydrogels. Acta Biomater. 2019, 90, 1-20. [CrossRef] [PubMed]

2. Hu, W.; Wang, Z.; Xiao, Y.; Zhang, S.; Wang, J. Advances in crosslinking strategies of biomedical hydrogels. Biomater. Sci. 2019, 7, 843-855. [CrossRef] [PubMed]

3. Caló, E.; Khutoryanskiy, V.V. Biomedical applications of hydrogels: A review of patents and commercial products. Eur. Polym. J. 2015, 65, 252-267. [CrossRef]

4. Laftah, W.A.; Hashim, S.; Ibrahim, A.N. Polymer hydrogels: A review. Polym. Plast. Technol. Eng. 2011, 50, 1475-1486. [CrossRef]

5. Maciel, V.B.V.; Yoshida, C.M.P.; Franco, T.T. Chitosan/pectin polyelectrolyte complex as a pH indicator. Carbohydr. Polym. 2015. [CrossRef]

6. Bernkop-Schnürch, A.; Dünnhaupt, S. Chitosan-based drug delivery systems. Eur. J. Pharm. Biopharm. 2012, 81, 463-469. [CrossRef]

7. Rampino, A.; Borgogna, M.; Blasi, P.; Bellich, B.; Cesàro, A. Chitosan nanoparticles: Preparation, size evolution and stability. Int. J. Pharm. 2013, 455, 219-228. [CrossRef]

8. Neufeld, L.; Bianco-peled, H. Pectin-Chitosan physical hydrogels as potential drug delivery vehicles. Int. J. Biol. Macromol. 2017, 101, 852-861. [CrossRef]

9. Hiorth, M.; Kjøniksen, A.L.; Knudsen, K.D.; Sande, S.A.; Nyström, B. Structural and dynamical properties of aqueous mixtures of pectin and chitosan. Eur. Polym. J. 2005, 41, 1718-1728. [CrossRef]

10. Ventura, I.; Bianco-Peled, H. Small-angle X-ray scattering study on pectin-chitosan mixed solutions and thermoreversible gels. Carbohydr. Polym. 2015, 123, 122-129. [CrossRef]

11. Marudova, M.; MacDougall, A.J.; Ring, S.G. Pectin-chitosan interactions and gel formation. Carbohydr. Res. 2004, 339, 1933-1939. [CrossRef]

12. Bernabé, P.; Peniche, C.; Argüelles-Monal, W. Swelling behavior of chitosan/pectin polyelectrolyte complex membranes. Effect of thermal cross-linking. Polym. Bull. 2005, 55, 367-375. [CrossRef]

13. Pakulska, M.M.; Vulic, K.; Tam, R.Y.; Shoichet, M.S. Hybrid Crosslinked Methylcellulose Hydrogel: A Predictable and Tunable Platform for Local Drug Delivery. Adv. Mater. 2015, 5002-5008. [CrossRef] [PubMed]

14. Kharkar, P.M.; Rehmann, M.S.; Skeens, K.M.; Maverakis, E.; Kloxin, A.M. Thiol-ene Click Hydrogels for Therapeutic Delivery. ACS Biomater. Sci. Eng. 2016, 2, 165-179. [CrossRef] [PubMed]

15. Lowe, A.B. Thiol-ene "click" reactions and recent applications in polymer and materials synthesis: A first update. Polym. Chem. 2014, 5, 4820-4870.

16. Hoyle, C.E.; Bowman, C.N. Thiol-Ene Click Chemistry. Angew. Chem. Int. Ed. 2010, 49, 1540-1573. [CrossRef]

17. Yom-tov, O.; Seliktar, D.; Bianco-peled, H. PEG-Thiol based hydrogels with controllable properties. Eur. Polym. J. 2016, 74, 1-12. [CrossRef]

18. Shitrit, Y.; Bianco-Peled, H. Acrylated chitosan for mucoadhesive drug delivery systems. Int. J. Pharm. 2017, 517, 247-255. [CrossRef]

19. Majzoob, S.; Atyabi, F.; Dorkoosh, F.; Kafedjiiski, K.; Loretz, B.; Bernkop-Schnürch, A. Pectin-cysteine conjugate: Synthesis and in-vitro evaluation of its potential for drug delivery. J. Pharm. Pharmacol. 2006, 58, 1601-1610. [CrossRef]

20. Eshel-Green, T.; Eliyahu, S.; Avidan-Shlomovich, S.; Bianco-Peled, H. PEGDA hydrogels as a replacement for animal tissues in mucoadhesion testing. Int. J. Pharm. 2016, 506. [CrossRef]

21. Josef, E.; Barat, K.; Barsht, I.; Zilberman, M.; Bianco-Peled, H. Composite hydrogels as a vehicle for releasing drugs with a wide range of hydrophobicities. Acta Biomater. 2013, 9, 8815-8822. [CrossRef] [PubMed]

22. Zhu, J. Bioactive modification of poly(ethylene glycol) hydrogels for tissue engineering. Biomaterials 2010, 31, 4639-4656. [CrossRef] [PubMed]

23. Birch, N.P.; Schiffman, J.D. Characterization of self-Assembled polyelectrolyte complex nanoparticles formed from chitosan and pectin. Langmuir 2014. [CrossRef] [PubMed]

24. Morris, G.A.; Kök, S.M.; Harding, S.E.; Adams, G.G. Polysaccharide drug delivery systems based on pectin and chitosan. Biotechnol. Genet. Eng. Rev. 2010, 27, 257-284. [CrossRef] [PubMed]

25. Sarika, P.R.; Pavithran, A.; James, N.R. Cationized gelatin/gum arabic polyelectrolyte complex: Study of electrostatic interactions. Food Hydrocoll. 2015, 49, 176-182. [CrossRef]

26. Haug, I.J.; Draget, K.I.; Smidsrød, O. Physical behaviour of fish gelatin-k-carrageenan mixtures. Carbohydr. Polym. 2004, 56, 11-19. [CrossRef] 
27. Bigucci, F.; Luppi, B.; Cerchiara, T.; Sorrenti, M.; Bettinetti, G.; Rodriguez, L.; Zecchi, V. Chitosan/pectin polyelectrolyte complexes: Selection of suitable preparative conditions for colon-specific delivery of vancomycin. Eur. J. Pharm. Sci. 2008, 35, $435-441$. [CrossRef]

28. Mamathambika, B.S.; Bardwell, J.C. Disulfide-Linked Protein Folding Pathways. Annu. Rev. Cell Dev. Biol. 2008, 24, 211-235. [CrossRef]

29. Zhang, X.; Yang, D.; Nie, J. Chitosan/polyethylene glycol diacrylate films as potential wound dressing material. Int. J. Biol. Macromol. 2008, 43, 456-462. [CrossRef]

30. Bearat, H.H.; Lee, B.H.; Vernon, B.L. Comparison of properties between NIPAAm-based simultaneously physically and chemically gelling polymer systems for use in vivo. Acta Biomater. 2012, 8, 3629-3642. [CrossRef]

31. Sriamornsak, P. Chemistry of Pectin and Its Pharmaceutical Uses: A Review. Silpakorn Univ. J. Soc. Sci. Humanit. Arts 2003, 3, 206-228.

32. Rizzi, S.C.; Hubbell, J.A. Recombinant protein-co-PEG networks as cell-adhesive and proteolytically degradable hydrogel matrixes. Part I: Development and physicochemical characteristics. Biomacromolecules 2005, 6, 1226-1238. [CrossRef] [PubMed]

33. Yom-tov, O.; Neufeld, L.; Seliktar, D.; Bianco-peled, H. A novel design of injectable porous hydrogels with in situ pore formation. Acta Biomater. 2014, 10, 4236-4246. [CrossRef] [PubMed]

34. Cerar, J.; Jamnik, A.; Tomšič, M. Testing classical approach to polymer solutions on SAXS data of $\lambda$-Carrageenan, $\mathrm{k}$-Carrageenan and methylcellulose systems. Acta Chim. Slov. 2015, 62, 498-508. [CrossRef] [PubMed]

35. Josef, E.; Bianco-Peled, H. Sponges carrying self-microemulsifying drug delivery systems. Int. J. Pharm. 2013, 458, 208-217. [CrossRef] [PubMed]

36. Cohen, Y.; Ramon, O.; Kopelman, I.J.; Mizrahi, S. Characterization of inhomogeneous polyacrylamide hydrogels. J. Polym. Sci. Part B Polym. Phys. 1992, 30, 1055-1067. [CrossRef]

37. Chandra, M.V.; Shamasundar, B.A. Texture profile analysis and functional properties of gelatin from the skin of three species of fresh water fish. Int. J. Food Prop. 2015, 18, 572-584. [CrossRef]

38. Tamburic, S.; Craig, D.Q.M. A comparison of different in vitro methods for measuring mucoadhesive performance. Eur. J. Pharm. Biopharm. 1997, 44, 159-167. [CrossRef]

39. Böcking, T.; Salomon, A.; Cahen, D.; Gooding, J.J. Thiol-terminated monolayers on oxide-free Si: Assembly of semiconductoralkyl-S-metal junctions. Langmuir 2007, 23, 3236-3241. [CrossRef]

40. Bartz, M.; Weber, N.; Küther, J.; Seshadri, R.; Tremel, W. "Sticky" gold colloids through protection-deprotection and their use in complex metal-organic-inorganic architectures. Chem. Commun. 1999, 2085-2086. [CrossRef]

41. Li, J.; Li, L.; Du, X.; Feng, W.; Welle, A.; Trapp, O.; Grunze, M.; Hirtz, M.; Levkin, P.A. Reactive superhydrophobic surface and its photoinduced disulfide-ene and thiol-ene (Bio)functionalization. Nano Lett. 2015, 15, 675-681. [CrossRef] [PubMed]

42. Bernkop-schnu, A. Thiomers: A new generation of mucoadhesive polymers B. Adv. Drug Deliv. Rev. 2005, 57, 1569-1582. [CrossRef] [PubMed]

43. Wei Shen, G.L.N. The adsorption and bonding of methanethiol on aluminium. J. Frankl. Inst. 1993, 296, 49-56. [CrossRef]

44. Khutoryanskiy, V.V. Advances in Mucoadhesion and Mucoadhesive Polymers. Macromol. Biosci. 2011, 11, 748-764. [CrossRef] [PubMed]

45. Smart, J.D. The basics and underlying mechanisms of mucoadhesion. Adv. Drug Deliv. Rev. 2005, 57, 1556-1568. [CrossRef]

46. Bernkop-Schnürch, A.; Greimel, A. Thiomers: The next generation of mucoadhesive polymers. Am. J. Drug Deliv. 2005, 3, 141-154. [CrossRef]

47. Davidovich-Pinhas, M.; Bianco-Peled, H. Novel mucoadhesive system based on sulfhydryl-acrylate interactions. J. Mater. Sci. Mater. Med. 2010, 21, 2027-2034. [CrossRef]

48. Cook, M.T.; Smith, S.L.; Khutoryanskiy, V.V. Novel glycopolymer hydrogels as mucosa-mimetic materials to reduce animal testing. Chem. Commun. 2015, 51, 14447-14450. [CrossRef]

49. Da Silva, J.B.; Khutoryanskiy, V.V.; Bruschi, M.L.; Cook, M.T. A mucosa-mimetic material for the mucoadhesion testing of thermogelling semi-solids. Int. J. Pharm. 2017, 528, 586-594. [CrossRef]

50. Cook, M.T.; Khutoryanskiy, V.V. Mucoadhesion and mucosa-mimetic materials-A mini-review. Int. J. Pharm. 2015, 495, 991-998. [CrossRef]

51. Dozli, L.; Bianco-Peled, H. Pectin-Thiol Hydrogels as Mucosa-Mimetic Surfaces to Replace Animals in Mucoadhesion Testing. Research Thesis, Technion-Israel Institute of Technology, Haifa, Israel, 2017.

52. Boskey, E.R.; Cone, R.A.; Whaley, K.J.; Moench, T.R. Origins of vaginal acidity: High D/L lactate ratio is consistent with bacteria being the primary source. Hum. Reprod. 2001, 16, 1809-1813. [CrossRef] [PubMed]

53. Leal, J.; Smyth, H.D.C.; Ghosh, D. Physicochemical properties of mucus and their impact on transmucosal drug delivery. Int. J. Pharm. 2017, 532, 555-572. [CrossRef] [PubMed] 